\title{
Subclavian Vein Cannulation and its Common Technical Errors, Failure Rates and Complications: A Cross-sectional Study
}

PRAVINKUMAR CHANDRAMANI GOVANDE', ANKUSH GANGARAM AASOLE², SUNIL NAVASAJI BOMBLE

\begin{abstract}
Introduction: Central Venous Catheter (CVC) is indicated when peripheral vein administration is not possible which can be inserted via different routes. CVC play a significant role in the therapeutic armamentarium of the surgeon and intensivist. The subclavian vein is the most frequently used access site but is associated with certain risks and failures.
\end{abstract}

Aim: To study common technical errors, failure rate and complications associated with subclavian cannulation.

Materials and Methods: This was a cross-sectional observational study carried out on 100 patients admitted from October 2017 to October 2020 for various surgical diseases in a Swami Ramanand Teerth Rural Government Medical College, Ambajogai, Maharashtra, India, requiring CVC placement. Subclavian vein cannulation (SVC) technique was done as standard method. Surgeon or anaesthetist who was performing the procedure noted the number of insertion attempts, failures and complications. Data was collected and analysed using Statistical Package for the Social Sciences (SPSS) version 21.0 and paired t-test. Level of significance was set at $p$-value $<0.05$.
Results: Total of 100 patients included in the study, 57 (57\%) were male with mean age of $61 \pm 14.2$ years and $43(43 \%)$ were female with mean age of $58 \pm 11.7$ years. SVC was successfully done in all 100 cases but in 236 attempts. Thus, 136 attempts were failure and the overall failure rate was $57.62 \%$. On an average there are 2.4 failed attempts per line. The most common technical error observed was improper site for needle insertion relative to the clavicle $27.94 \%$ followed by insertion of the needle through the clavicular periosteum $25.74 \%$. The overall complication rate was $9 \%$ and most common complications was haematoma in $6 \%$, catheter site infection $2 \%$ and pneumothorax in $1 \%$.

Conclusion: Subclavian vein catheterisation is an important invasive procedure often performed to administer drugs, haemodynamic monitoring and total parenteral nutrition. It is associated with high failure rate and complications due to technical errors of judgement leading to multiple attempts of needle insertion. They can be minimised with knowledge of anatomical landmarks, ultrasound guidance and Subclavian Vein Cannulation (SVC) personnel experience.

Keywords: Central venous pressure, Localised phlebitis, Parenteral nutrition

\section{INTRODUCTION}

Most patients admitted to an intensive care unit undergo intravenous cannulation with peripheral venous cannulation being the first choice as they have large bore which facilitate rapid fluid infusion, so they are commonly used $[1,2]$. However, they require replacement every 72 hours due to significant rates of localised phlebitis [3]. They should not be used to infuse vasoactive medications as extravasation of these medications can lead to tissue loss and significant morbidity. In an emergency, peripheral venous cannulation should be treated as contaminated so that risk of septic phlebitis can be avoided [3].

Central Venous Catheter (CVC) is indicated when peripheral vein administration is not possible which can be inserted via different routes [4]. A Peripherally Inserted Central Catheter (PICC) is a popular route for central venous access as they significantly minimise the risks of haemothorax and pneumothorax associated with CVC placement but they are associated with significantly greater rates of phlebitis and catheter malfunction [5].

Central Venous Catheter (CVC) play a significant role in the therapeutic armamentarium of the surgeon and intensivist. The subclavian vein is the most frequently used access site [6]. Current evidence supports the fact that subclavian vein catheter infection rate is lower $(4 / 1000$ catheter-days) than rates for both internal jugular (8.6/1000 catheter -days) and femoral catheters (15.3/1000 catheter- days) [7]. The subclavian vein is more accessible to operators in trauma patients with cervical collars than internal jugular. In addition, the subclavian catheter is often placed without disrupting airway management during the initial stage of resuscitation [8]. The femoral vein can be cannulated without disrupting airway management, but, stated earlier there is a higher rate of femoral catheter rate infection [9].

Indications for central line placement includes haemodynamic monitoring (Central venous pressure), infusion of long term antibiotics, kesol infusion or chemotherapy, infusion of vasoactive substances, aspiration of air embolism, temporary dialysis access and poor peripheral venous access. Absolute contraindications are infection at insertion site, anatomic obstruction (thrombosis, anatomic variance), superior vena cava syndrome while coagulopathy, systemic infection, presence of pacing wires or other indwelling catheters at insertion site and right ventricular assist device relative contraindications [10].

The CVC use is associated with certain inherent risks of complication related with catheter and/or patient related factors. Catheter placement related complication rate ranges from 5-9\% of catheter insertions and rate of catheter related infection ranges from 5-26\% which can be reduced by focusing on two specific phases CVC insertion and daily maintenance $[3,11]$. This work was aimed to study common technical errors, failure rate of subclavian cannulation, and complications associated with subclavian cannulation.

\section{MATERIALS AND METHODS}

This was a cross-sectional observational study carried out on 100 patients admitted from October 2017 to October 2020 for various surgical diseases in a Swami Ramanand Teerth Rural Government Medical College and Hospital, Ambajogai, Beed, Maharashtra, India. 
Study was approved by Institutional Ethics Committee (SRTRGMC/ Pharm/Surg/90/2017-18). A written informed consent was taken from each participant.

Inclusion and Exclusion criteria: All patients above 15 years who were critically ill and require parenteral nutrition, long term intravenous antibiotic, intensive care unit, inaccessible peripheral vein were included and patient with distorted local anatomy, patients with coagulation disorders, infection at insertion site and uncooperative patients were excluded.

\section{Study Procedure}

Subclavian vein cannulation technique was done as standard method [12]. After explaining the procedure to the patient and the potential risks and benefits, informed consent was taken. Patient was made to lie down in supine position and Trendelenburg position and monitored with bedside monitor or pulse oximeter throughout procedure. The proposed catheter insertion site and surrounding skin (approximately, 10 inches in diameter) was prepared with the povidone iodine solution. CVC and all lumens including their corresponding hubs and caps were checked. Using an angle of 10-15 degrees beneath the clavicle, an 18 or 20 gauze needle was inserted directing towards suprasternal notch then walk the needle below the clavicle. For an introducer, the side-arm was detached and the guidewire was inserted through the introducer lumen. The guidewire was advanced into the superior vena cava while communicating with patient to ensure that they remain conscious. If arrhythmias develop, the guidewire was removed until they stop. The CVC was pass over the guide wire and inserted to an appropriate position based on patient's size. Blood was aspirated from all ports to confirm position. All ports were flushed with sterile saline and catheter was fixed to skin using sutures and adhesive tape. Time and date of CVC insertion were documented in medical record. The number of insertion attempts and failures was noted for each procedure. An attempt was defined as a puncture of the skin with the cannulating needle. An attempt was successful when the subclavian vein was entered and the guidewire successfully passed. An attempt was defined as unsuccessful if the needle was removed without having the guidewire in place (the vein was not cannulated, the wire was in a fascial plane or the wire was not pass even if the needle was in the vein). Ultrasonographic guidance was not used in any of the placement attempts. Surgeon or anaesthetist, who was performing the procedure, determined the main cause for failure of a line placement. If there was difficulty in determining the cause for the line failure, then senior person was consulted. If the cause of failure was not found, then the case was not included in the study. Surgeon or anaesthetist, who was performing the procedure, determine the complications during procedure like haematoma, arterial puncture and cardiac arrhythmia and post procedure chest X-ray was done to detect pneumothorax, haemothorax, mediastinal haematoma and the catheter insertion site was examined daily to monitor for infection.

\section{STATISTICAL ANALYSIS}

The data from the study subjects was recorded and analysed using Statistical Package for the Social Sciences (SPSS) version 21.0 (by IBM, based in Chicago, Illinois). Descriptive data described as frequencies, percentages, mean and standard deviation, association between different study variables such as number of attempts, failure rate and complications was done using paired t-test. Level of significance was set at $\mathrm{p}$-value $<0.05$.

\section{RESULTS}

Total of 100 patients included in the study, 57 (57\%) were male with mean age of $61 \pm 14.2$ years and $43(43 \%)$ were female with mean age of $58 \pm 11.7$ years. Male to female ratio was $2: 1.5$. The most common indication was the requirement of long term antibiotics, kesol infusion and chemotherapy [Table/Fig-1].

In the present study of total 100 cases, SVC was successfully done in all cases but in 236 attempts. Thus, $136(236-100=136)$ attempts

\begin{tabular}{|l|c|}
\hline Indications & $\begin{array}{c}\text { No. of cases } \\
(\mathrm{n}=100)\end{array}$ \\
\hline Infusion of vasoactive substances & 25 \\
\hline Poor peripheral venous access & 16 \\
\hline Infusion of long term antibiotics, kesol infusion, chemotherapy & 37 \\
\hline Haemodynamic monitoring & 22 \\
\hline Aspiration of air embolism & 0 \\
\hline Temporary dialysis access & 0 \\
\hline [Table/Fig-1]: Indications of subclavian cannulation. & \\
\hline
\end{tabular}

were failure and the overall attempts failure rate was $57.62 \%$. (right side $60.38 \%$ and left side was $37.9 \%$ ). On an average, there were 2.4 failed attempts per line (1.6 on left side and 2.5 on right side; $p$-value $=0.008$ ), calculated using Student's t test. This shows that the failure of attempts was more on right sided than on left sided cannulation [Table/Fig-2].

\begin{tabular}{|l|c|c|c|c|c|}
\hline Site & $\begin{array}{c}\text { No. of } \\
\text { cases }\end{array}$ & $\begin{array}{c}\text { No. of } \\
\text { attempts }\end{array}$ & $\begin{array}{c}\text { Failed } \\
\text { attempt }\end{array}$ & $\begin{array}{c}\text { Failure } \\
\text { rate }\end{array}$ & $\begin{array}{c}\text { Attempt } \\
\text { per line }\end{array}$ \\
\hline Right side & 82 & 207 & 125 & $60.38 \%$ & 2.5 \\
\hline Left side & 18 & 29 & 11 & $37.93 \%$ & 1.6 \\
\hline Total & 100 & 236 & 136 & $57.62 \%$ & 2.4 \\
\hline
\end{tabular}

The most common technical error observed was improper site for needle insertion relative to the clavicle (27.94\%) followed by insertion of the needle through the clavicular periosteum (25.74\%) [Table/Fig-3].

\begin{tabular}{|l|c|c|}
\hline Technical error & $\begin{array}{c}\text { Frequency of errors } \\
(\mathbf{n}=136)\end{array}$ & $\begin{array}{c}\text { Percentages } \\
(\%)\end{array}$ \\
\hline Improper landmark identification & 22 & 16.18 \\
\hline Improper insertion relative to clavicle & 38 & 27.94 \\
\hline Insertion through periosteum & 35 & 25.74 \\
\hline Too shallow trajectory & 16 & 11.76 \\
\hline Aiming to cephalad & 14 & 10.29 \\
\hline Failure to keep needle in place & 11 & 8.09 \\
\hline
\end{tabular}

[Table/Fig-3]: Subclavian catheter placement technical errors and percentages of failures.

The overall complication rate was 9\%. The most common complications were haematoma in $6 \%$, catheter site infection $2 \%$ and pneumothorax in 1\% [Table/Fig-4].

\begin{tabular}{|l|c|}
\hline Complications & No. of cases $(\mathrm{n}=100)$ \\
\hline Haematoma & 6 \\
\hline Pneumothorax & 1 \\
\hline Haemothorax & 0 \\
\hline Infection at catheter site & 2 \\
\hline Thrombosis & 0 \\
\hline Arrhythmia & 0 \\
\hline Total & 9 \\
\hline [Table/Fig-4]: Complications of subclavian cannulation. \\
\hline
\end{tabular}

In present study, 37\% cases are cannulated on first attempt and 63\% case is cannulated on more than one attempts. The complication rate is nil in single or double attempt and $25.71 \%$ for three or more passes [Table/Fig-5].

\begin{tabular}{|l|c|c|}
\hline Total no. of attempts & No. of cases $(\mathrm{n}=\mathbf{1 0 0})$ & No. of cases with complications \\
\hline 1 & 37 & 0 \\
\hline 2 & 28 & 0 \\
\hline 3 & 14 & 1 \\
\hline 4 & 10 & 1 \\
\hline 5 & 5 & 2 \\
\hline 6 & 6 & 5 \\
\hline
\end{tabular}




\section{DISCUSSION}

The CVCs are commonly inserted for haemodynamic monitoring, administration of medications, long-term total parenteral nutrition, access or renal replacement therapy, cardiopulmonary resuscitation and difficult peripheral catheterisation [10].

In present study, the subclavian vein was cannulated in all 100 cases but in 236 attempts. That means 136 more attempts with failure rate of $57.62 \%$. The average number of failed venipuncture per line was 2.4 (left-side 1.6 attempts, right side 2.5 attempts; $p$ value=0.008) indicating predominance of failure on right side as all right handed operator use their dominant hand for cannulation, therefore most comfortable position seemed to be on patients left side. There is no anatomic or patient related reason for this. Killbourne $\mathrm{MJ}$ et al., studied the videotaped CVC insertions of 86 patients [13]. The overall needle insertion failure rate was $78.2 \%$. The mean number of failed attempts per successful CVC insertion was 3.2 (5.5 on the right and 2.1 on the left; $p=0.016$ ). A study done by Sidoti $A$ et al., on 74 patients in each group of ultrasound guided and landmark groups reported mean number of attempts of 1.14 and $2.08(p<0.001)$, respectively, which was comparable to findings in this study [14].

The most common technical error noted was improper needle insertion position relative to the clavicle due to the close proximity of clavicle. These data are almost comparable to the study done by Kilbourne MJ et al., in which six most common technical errors in subclavian vein cannulation were noted and improper insertion position relative to the clavicle $(32.3 \%)$, insertion of the needle through the clavicular periosteum (21.9\%) accounted for maximum number of cases [13].

Overall complication rate noted in present study was 9\% and haematoma, being the most common complication accounting for $6 \%$ of cases. Inadvertent puncture of subclavian artery due to passage of needle directing too far laterally and posterior is the reason behind formation of haematoma. In this study, haematoma was $6 \%$ which is higher than another study by Kilbourne MJ et al., in which rate was 1.5\% to 3.1\% [13]. Lefrant JY et al., also reported haematoma formation in $7.8 \%$ patient due to arterial puncture [15]. Thakur A et al., in their study on 60 patients reported haematoma (1\%) being the only complication [16].

According to Graham AS et al., catheter site infection is associated with increase cost and morbidity with burden on healthcare facility with $4 \%$ rate of catheter site infection [7]. Use of sterile catheter insertion technique with proper dressing and daily maintenance can decrease the rate of infection. Lee $\mathrm{JH}$ et al., in their study on 746 patients reported catheter site infection in $6.2 \%$ patients [17]. In this study, it was seen in $2 \%$ cases only.

Patients who require CVC are also at high risk for catheterrelated thrombosis as a result of their critical illness. Thrombotic complications occur in 2-26\% of patients in a study by Czarnik T et al., [18]. Present study has not reported any such incidence [18].

Puncture of parietal pleura during needle insertion may leads to pneumothorax or pneumomediastinum formation observed commonly in subclavian vein CVC. As observed by McGee DC et al., complication of pneumothorax formation is 1\% [11]. Kilbourne MJ et al., in their study also observed pneumothorax in 1.2\%-2.1\% cases [13]. Parienti JJ et al., in their study on 843 patients revealed pneumothorax in $2.1 \%$ of patients [19]. One percent of the patients in this study also demonstrated pneumothorax.

Multiple venipunctures can increase the complications rate of central line placement. In this study, complication rate was nil in single or double attempts and $25.71 \%$ when attempts are three or more. These data were almost similar to Mansfield PF et al., which studied the success and complications associated with subclavian vein catheterisation in 821 patients [6]. If only a single needle pass was attempted, the complication rate was $4 \%$, as compared with $11 \%$ for two passes, and $24 \%$ for three or more passes.
Gualtieri $\mathrm{E}$ et al., in their analysis on 52 catheterisation procedures shown that 12 (44\%) catheters were successfully placed from 27 attempts using the landmark technique vs. 23 (92\%) successful catheterisations during 25 ultrasound procedures which highlights ultrasound guided catheterisation use to significantly improve the success rate of subclavian venous catheterisation [20]. The use of surface anatomical landmarks is critical to the success of these procedures and use of ultrasound localisation adds a dimension of orientation [20].

After reviewing literature, all the common technical errors associated with subclavian vein cannulation were included in present study with standard procedure of subclavian vein cannulation. Future recommendation includes more number of study subjects with longer follow-up.

\section{Limitation(s)}

The principal limitations of this study was sample size, more number of study subjects involved may decrease the uncoverage bias. The cause for failure of a line placement decided by operator or senior doctor lead to operator bias which can be minimised by video recording during cannulation. The number of cases on right and left side are not equal and there is gross disparity which could have influence the results. The number of attempts of cannulation can be decreased, if performed under ultrasound guidance which is not done in this study.

\section{CONCLUSION(S)}

Subclavian vein catheterisation is an important invasive procedure associated with most common technical error of improper needle insertion position relative to the clavicle. Multiple attempts of needle insertion lead to complications of which haematoma being the most common.

\section{REFERENCES}

[1] Tager IB, Ginsberg MB, Ellis SE, Walsh NE, Dupont I, Simchen E, et al. An epidemiologic study of the risks associated with peripheral intravenous catheters. Am J Epidemiol. 1983;118(6):839-51. Doi: 10.1093/oxfordjournals.aje.a113702. PMID: 6650485

[2] Rosen KR, Rosen DA. Comparative flow rates for small bore peripheral intravenous catheters. Pediatr Emerg Care. 1986;2(3):153-56. Doi: 10.1097/00006565198609000-00001. PMID: 3786219.

[3] Millikan JS, Cain TL, Hansbrough J. Rapid volume replacement for hypovolemic shock: A comparison of techniques and equipment. J Trauma. 1984;24(5):42831. Doi: 10.1097/00005373-198405000-00010. PMID: 6716521.

[4] Dailey RH. "Code Red" protocol for resuscitation of the exsanguinated patient. J Emerg Med. 1985;2:373-78.

[5] Kornbau C, Lee KC, Hughes GD, Firstenberg MS. Central line complications. Int J Crit IIIn Inj Sci. 2015;5(3):170-78. Doi: 10.4103/2229-5151.164940. PMID: 26557487; PMCID: PMC4613416.

[6] Mansfield PF, Hohn DC, Fornage BD, Gregurich MA, Ota DM. Complications and failures of subclavian-vein catheterisation. N Engl J Med. 1994;331(26):1735-38. Doi: 10.1056/NEJM199412293312602. PMID: 7984193.

[7] Graham AS, Ozment C, Tegtmeyer K, Lai S, Braner DA. Videos in clinical medicine. Central venous catheterisation. N Engl J Med. 2007;356(21):e21. Doi: 10.1056/NEJMvcm055053. PMID: 17522396.

[8] TaylorRW, Palagiri AV. Central venous catheterisation. Crit Care Med. 2007;35(5):1390 96. Doi: 10.1097/01.CCM.0000260241.80346.1B. PMID: 17414086.

[9] Tsotsolis N, Tsirgogianni K, Kioumis I, Pitsiou G, Baka S, Papaiwannou A, et al. Pneumothorax as a complication of central venous catheter insertion. Ann Trans Med. 2015;3(3):40. Doi: 10.3978/j.issn.2305-5839.2015.02.11. PMID: 25815301; PMCID: PMC4356862.

[10] Tse A, Schick MA. Central Line Placement. [Updated 2020 Aug 15]. In: StatPearls [Internet]. Treasure Island (FL): StatPearls Publishing; 2021 Jan.

[11] McGee DC, Gould MK. Preventing complications of central venous catheterisation. N Engl J Med. 2003;348(12):1123-33. Doi: 10.1056/NEJMra011883. PMID: 12646670.

[12] Bannon MP, Heller SF, Rivera M. Anatomic considerations for central venous cannulation. Risk Manag Healthc Policy. 2011;4:27-39. Doi: 10.2147/RMHP. S10383. Epub 2011 Apr 13. PMID: 22312225; PMCID: PMC3270925.

[13] Kilbourne MJ, Bochicchio GV, Scalea T, Xiao Y. Avoiding common technical errors in subclavian central venous catheter placement. J Am Coll Surg. 2009;208(1):10409. Doi: 10.1016/j.jamcollsurg.2008.09.025. PMID: 19228511.

[14] Sidoti A, Brogi E, Biancofiore G, Casagli S, Guarracino F, Malacarne P, et al. Ultrasound- versus landmark-guided subclavian vein catheterisation: A prospective observational study from a tertiary referral hospital. Sci Rep. 2019;9:12248. https:// doi.org/10.1038/s41598-019-48766-1. 
[15] Lefrant JY, Muller L, De La Coussaye JE, Prudhomme M, Ripart J, Gouzes $\mathrm{C}$, et al. Risk factors of failure and immediate complication of subclavian vein catheterisation in critically ill patients. Intensive Care Med. 2002;28(8):1036-41. Doi: 10.1007/s00134-002-1364-9. Epub 2002 Jul 6. PMID: 12185422.

[16] Thakur A, Kaur K, Lamba A, Taxak S, Dureja J, Singhal S, et al. Comparative evaluation of subclavian vein catheterisation using supraclavicular versus infraclavicular approach. Indian J Anaesth. 2014;58:160-64.

[17] Lee JH, Kim ET, Shim DJ, Kim IJ, Byeon JH, Lee IJ, et al. Prevalence and predictors of peripherally inserted central catheter-associated bloodstream infections in adults: A multicenter cohort study. PLoS ONE. 2019;14(3):e0213555. https:// doi.org/10.1371/journal.pone.0213555.
[18] Czarnik T, Gawda R, Perkowski T, Weron R. Supraclavicular approach is an easy and safe method of subclavian vein catheterisation even in mechanically ventilated patients: Analysis of 370 attempts. Anaesthesiology. 2009;111:33439. Doi: https://doi.org/10.1097/ALN.0b013e3181ac461f.

[19] Parienti JJ, Mongardon N, Mégarbane B, Mira JP, Kalfon P, Gros A, et al. Intravascular complications of central venous catheterisation by insertion site. N Engl J Med. 2015;373(13):1220-29. https://doi.org/10.1056/NEJMoa1500964.

[20] Gualtieri E, Deppe SA, Sipperly ME, Thompson DR, Subclavian venous catheterisation: Greater success rate for less experienced operators using ultrasound guidance. Crit Care Med. 1995;23(4):692-97. Doi: 10.1097/00003246199504000-00018. PMID: 7661944.

\section{PARTICULARS OF CONTRIBUTORS}

1. Assistant Professor, Department of General Surgery, Swami Ramanand Teerth Rural Government Medical College, Ambajogai, Maharashtra, India

2. Assistant Professor, Department of General Surgery, Swami Ramanand Teerth Rural Government Medical College, Ambajogai, Maharashtra, India.

3. Assistant Professor, Department of General Surgery, Dr. Shankarrao Chavan Government Medical College, Nanded, Maharashtra, India.

4. Assistant Professor, Department of General Surgery, Swami Ramanand Teerth Rural Government Medical College, Ambajogai, Maharashtra, India.

5. Senior Resident, Department of General Surgery, Swami Ramanand Teerth Rural Government Medical College, Ambajogai, Maharashtra, India.

\section{NAME, ADDRESS, E-MAIL ID OF THE CORRESPONDING AUTHOR:}

Dr. Ravikumar Nathrao Phad,

7, Sinhgad, SRTR GMC Campus, Ambajogai, Maharashtra, India. E-mail: ravi88gmcite@gmail.com
PLAGIARISM CHECKING METHODS: [Jain Het al]

- Plagiarism X-checker: May 27, 2021

- Manual Googling: Aug 10, 2021

- iThenticate Software: Sep 01, 2021 (15\%)

\section{AUTHOR DECLARATION:}

- Financial or Other Competing Interests: None

- Was Ethics Committee Approval obtained for this study? Yes

- Was informed consent obtained from the subjects involved in the study? Yes

- For any images presented appropriate consent has been obtained from the subjects.

ETYMOLOGY: Author Origin

Date of Submission: May 21, 2021

Date of Peer Review: Jul 03, 2021

Date of Acceptance: Aug 11, 2021

Date of Publishing: Jan 01, 2022 